\title{
THE BIOLOGY AND ECOLOGY OF TUBER AESTIVUM MYCORRHIZAE ESTABLISHMENT IN THE GREENHOUSE AND THE FIELD
}

\author{
Grechen Pruett
}

Dr. Johann Bruhn, Dissertation Supervisors

\begin{abstract}
Truffles, of the ectomycorrhizal genus Tuber, are cultivated in plantations to offset declining wild production. Although methods for truffle plantation management have been published, methods for the production of trufflecolonized seedlings are rarely published. In a greenhouse study I tested the effect of lime type, inoculation technique, and truffle source on oak growth and mycorrhizal colonization. I found that the type of lime used to raise potting mix $\mathrm{pH}$ can affect the growth rate of root systems inoculated with Burgundy truffle (Tuber aestivum). I also report on the effects of two greenhouse seedling production systems on growth and colonization of oak seedlings. I found that book-type containers and a peat-based medium produced smaller yet better-colonized seedlings than seedlings produced in $\mathrm{RPM}^{\circledR}$ containers with ground bark-based RPM medium. Finally, I identified and monitored the ectomycorrhizal community on inoculated seedlings for three years and found that both $T$. aestivum colonization levels and native species richness increased in the field, indicating that native species, in the short term, did not displace $T$. aestivum.
\end{abstract}

